\title{
Predictors of weaning outcome in chronic obstructive pulmonary disease patients
}

\author{
R. Alvisi, C.A. Volta, E.R. Righini, M. Capuzzo, R. Ragazzi, M. Verri, G. Candini, \\ G. Gritti, J. Milic-Emili
}

Predictors of weaning outcome in chronic obstructive pulmonary disease patients. $R$. Alvisi, C.A. Volta, E.R. Righini, M. Capuzzo, R. Ragazzi, M. Verri, G. Candini, G. Gritti, J. Milic-Emili. (C) ERS Journals Ltd 2000.

ABSTRACT: Several threshold values for predicting weaning outcome from mechanical ventilation have been proposed. These values, however, have been obtained in nonhomogeneous patient populations. The aim of the present study was to determine the threshold values in chronic obstructive pulmonary disease (COPD) patients and compare them to those reported for nonhomogeneous patient populations.

The initial weaning trial included 81 COPD patients. Fifty-three of them underwent a successful weaning trial, whereas 28 failed it. The latter were enrolled into the present investigation, and were restudied during a subsequent successful trial. The weaning indices used were those reported in the literature.

The threshold values obtained were within $10 \%$ of those reported for a nonhomogeneous patients population only for tidal volume and effective compliance. The classification error was $<\mathbf{2 0} \%$ for maximal inspiratory pressure (MIP), occluded inspiratory pressure swing $(\Delta P \mathrm{I}) / \mathrm{MIP}$, rapid and shallow breathing (respiratory frequency/tidal volume), and compliance, rate, oxygenation, pressure index (CROP), whereas the area under the receiver operating characteristic curves was $>0.9$ only for $\triangle P I / M I P$ and CROP.

In conclusion, the threshold values obtained in chronic obstructive pulmonary disease patients who failed the first weaning attempt differed from those previously reported. Although a gold standard weaning index is not available for chronic obstructive pulmonary disease patients, the occluded inspiratory pressure swing/ maximal inspiratory pressure and compliance, rate, oxygenation, pressure index may be candidates for such a role.

Eur Respir J 2000; 15: 656-662.

Dept of Biomedical Science and Advanced Therapy, Section of Anesthesia and Intensive Care, Ospedale S.Anna, University of Ferrara, Ferrara, Italy. Meakins Christie Laboratories, McGill University, Montreal, Canada.

Correspondence: R. Alvisi, Dept of Biomedical Science and Advanced Therapy, Section of Anesthesia and Intensive Care, University of Ferrara, Corso Giovecca 203, 44100 Ferrara, Italy, Fax: 39 0532206570

Keywords: Chronic obstructive

pulmonary disease

classification error

receiver operating characteristic

threshold values

weaning indices

Received: April 221999

Accepted after revision November 291999

This study was supported, in part, by a grant from the Ministero dell'Università e della Ricerca Scientifica e Tecnologica
Numerous indices have been proposed for the prediction of weaning outcome from mechanical ventilation. Only a few, however, are of good diagnostic accuracy. YANG and ToBIN [1] established the threshold values of a battery of different weaning indices reflecting respiratory mechanics, pulmonary gas exchange, control of breathing and inspiratory muscle function in a highly nonhomogeneous patient population. Then they assessed the predictive power of the threshold value for each index in another nonhomogeneous patient population, and found that the rapid and shallow breathing index (the ratio of respiratory frequency $(f \mathrm{R})$ to tidal volume $(V \mathrm{~T})$ was the most accurate predictor of weaning outcome. However, the abnormalities of respiratory mechanics, gas exchange, control of breathing and inspiratory muscle function vary markedly among patients who require mechanical ventilation for different aetiologies [2-7]. Accordingly, the threshold values of the weaning indices should be assessed in homogeneous patient populations.

The aim of this study was to determine the threshold values of previously proposed weaning indices in a population of chronic obstructive pulmonary diseases (COPD) patients. The same patients were studied first during a failed weaning trial(WF) and than during a successful trial(WS).
Materials and methods

\section{Patients}

The initial weaning trial included 81 COPD patients admitted to the authors' intensive care unit (ICU; S. Anna Hospital) for management of acute respiratory failure (ARF). Fifty-three of them underwent a WS, and 28 a WF. The latter were enrolled in the present investigation, and were restudied during a subsequent WS. The anthropometric characteristics of the patients are given in table 1 . The diagnosis of COPD was based on clinical history, chest radiography and lung function tests (forced expiratory volume in one second (FEV1)/forced vital capacity (FVC) $<70 \%$ of the predicted value), according to American Thoracic Society criteria [8]. The FEV1/FVC at the time of discharge from the ICU was available for 22 patients and averaged $46 \pm 11 \%$ pred. The predicted values were those of Morris et al. [9]. The ARF was due to different aetiologies (table 1): 19 patients had airway infection, characterized by wheezing, increased sputum production, cough, fever and elevation of the white blood cell count; five had pneumonia as evidenced by typical radiographic findings. In three cases the cause of ARF 
Table 1. - Anthropometric and clinical characteristics of chronic obstructive pulmonary disease patients

\begin{tabular}{|c|c|c|c|c|c|c|c|c|c|}
\hline $\begin{array}{l}\text { Patient } \\
\text { No. }\end{array}$ & Sex & $\begin{array}{l}\text { Age } \\
\text { yrs }\end{array}$ & $\begin{array}{l}\text { Weight } \\
\text { kg }\end{array}$ & $\begin{array}{c}\text { Cause of } \\
\text { ARF }\end{array}$ & $\begin{array}{l}t \mathrm{ICU} \\
\text { days }\end{array}$ & $\begin{array}{l}t \mathrm{WF} \\
\text { days }\end{array}$ & $\begin{array}{l}t \mathrm{WS} \\
\text { days }\end{array}$ & $\begin{array}{c}\mathrm{FEV}_{1} * \\
\mathrm{~L}\end{array}$ & $\begin{array}{c}\mathrm{FVC}^{*} \\
\mathrm{~L}\end{array}$ \\
\hline 1 & M & 69 & 95 & Pneumonia & 11 & 5 & 6 & 0.93 & 1.90 \\
\hline 2 & $\mathrm{~F}$ & 76 & 48 & Airway infection & 45 & 15 & 33 & & \\
\hline 3 & $\mathrm{~F}$ & 76 & 90 & CHF; airway infection & 14 & 7 & 10 & 0.89 & 1.33 \\
\hline 4 & M & 76 & 113 & Airway infection & 18 & 7 & 11 & 1.32 & 2.18 \\
\hline 5 & $\mathrm{~F}$ & 74 & 100 & CHF; airway infection & 22 & 9 & 15 & & \\
\hline 6 & $\mathrm{~F}$ & 78 & 50 & & 10 & 5 & 7 & 0.56 & 0.90 \\
\hline 7 & $\mathrm{M}$ & 66 & 80 & Airway infection & 26 & 12 & 21 & 0.63 & 1.59 \\
\hline 8 & $\mathrm{~F}$ & 75 & 48 & Airway infection & 28 & 17 & 20 & 0.47 & 0.95 \\
\hline 9 & $\mathrm{~F}$ & 81 & 80 & Airway infection & 12 & 6 & 9 & 0.50 & 1.20 \\
\hline 10 & $\mathrm{M}$ & 72 & 85 & Pneumonia & 35 & 20 & 28 & 0.92 & 1.80 \\
\hline 11 & $\mathrm{M}$ & 75 & 70 & Pneumonia & 15 & 7 & 13 & 0.64 & 1.50 \\
\hline 12 & $\mathrm{~F}$ & 69 & 58 & Airway infection & 19 & 9 & 13 & 0.92 & 1.31 \\
\hline 13 & $\mathrm{M}$ & 65 & 78 & Sepsis & 42 & 13 & 15 & 0.78 & 1.20 \\
\hline 14 & M & 67 & 40 & Airway infection & 17 & 7 & 12 & & \\
\hline 15 & $\mathrm{~F}$ & 65 & 71 & & 14 & 5 & 7 & 0.78 & 1.56 \\
\hline 16 & $\mathrm{M}$ & 77 & 50 & Airway infection & 19 & 8 & 13 & 0.52 & 1.58 \\
\hline 17 & $\mathrm{~F}$ & 67 & 53 & Airway infection & 17 & 9 & 15 & 0.43 & 0.90 \\
\hline 18 & $\mathrm{~F}$ & 67 & 58 & Airway infection & 24 & 8 & 17 & 0.39 & 0.73 \\
\hline 19 & $\mathrm{~F}$ & 63 & 70 & CHF; airway infection & 37 & 12 & 26 & 0.91 & 1.87 \\
\hline 20 & M & 65 & 93 & Airway infection & 10 & 5 & 7 & 0.57 & 1.47 \\
\hline 21 & $\mathrm{~F}$ & 74 & 49 & Airway infection & 13 & 5 & 8 & & \\
\hline 22 & M & 79 & 53 & Airway infection & 9 & 5 & 7 & & \\
\hline 23 & M & 82 & 75 & Airway infection & 15 & 6 & 8 & 0.58 & 1.30 \\
\hline 24 & $\mathrm{~F}$ & 74 & 45 & Airway infection & 14 & 6 & 8 & & \\
\hline 25 & $\mathrm{~F}$ & 65 & 75 & & 9 & 5 & 8 & 0.32 & 0.96 \\
\hline 26 & $\mathrm{~F}$ & 65 & 87 & NHL; airway infection & 25 & 15 & 21 & 0.60 & 1.41 \\
\hline 27 & M & 67 & 67 & Pneumonia & 9 & 5 & 6 & 0.37 & 1.64 \\
\hline 28 & $\mathrm{M}$ & 79 & 70 & Pneumonia & 15 & 5 & 8 & 0.68 & 1.46 \\
\hline Mean & & 72 & 70 & & 19 & 8 & 13 & 0.67 & 1.39 \\
\hline SD & & 6 & 19 & & 10 & 4 & 8 & 0.25 & 0.38 \\
\hline
\end{tabular}

*: measurements made at time of discharge from intensive care unit (ICU). ARF: acute respiratory failure; $t$ ICU: time in ICU; $t$ WF: time on mechanical ventilation before a failed weaning trial; $t$ WS: time on mechanical ventilation before a successful weaning trial; FEV1: forced expiratory volume in one second; FVC: forced vital capacity; M: male; F: female; CHF: congestive heart failure; NHL: nonHodgkin's lymphoma.

could not be determined. All patients were hypercapnic when they were transferred to the ICU. At the time of discharge from the ICU, their arterial carbon dioxide tensions $\left(\mathrm{P}_{\mathrm{a}}, \mathrm{CO}_{2}\right)$ amounted to $7.3 \pm 1.1 \mathrm{kPa}(55 \pm 8 \mathrm{mmHg})$. On discharge, only three patients were not hypercapnic $\left(P a, \mathrm{CO}_{2}<5.7 \mathrm{kPa}(43 \mathrm{mmHg})\right)$, suggesting that most of the patients $(90 \%)$ had undergone acute on chronic respiratory failure.

The duration of mechanical ventilation at the time of the WF and the WS is shown in table 1. On average, $4.8 \pm 3.9$ days elapsed between the two trials. The study was approved by the Institutional Ethics Committee and informed consent was received from the patients or next of kin.

Patients were intubated with endotracheal tubes of 8.0$8.5 \mathrm{~mm}$ internal diameter. During the day they were ventilated with assist-control (A/C) mode or pressure support ventilation using a Servo 900C ventilator (Siemens-Elema, Solna, Sweden), as decided by their attending physician. Overnight, however, they were all placed on $\mathrm{A} / \mathrm{C}$ mode ventilation. The decision to attempt a weaning trial, extubate a patient or reinstitute mechanical ventilation was made by the primary physician who was blinded to the study design and did not know the values of the various weaning indices used in the present study (table 2). Such decisions were made according to the routine clinical
Table 2. - Threshold values for predicting weaning outcome

\begin{tabular}{|c|c|c|}
\hline \multirow[b]{2}{*}{ Weaning index } & \multicolumn{2}{|c|}{ Threshold value } \\
\hline & $\begin{array}{l}\text { Previous } \\
\text { studies* }\end{array}$ & $\begin{array}{c}\text { Present } \\
\text { study }\end{array}$ \\
\hline$f \mathrm{R}$ breaths $\cdot \min ^{-1}$ & $\leq 38$ & $\leq 25$ \\
\hline$V \mathrm{~T} \mathrm{~mL}$ & $\geq 325$ & $\geq 340$ \\
\hline$V \mathrm{~T} / \mathrm{BW} \mathrm{mL} \cdot \mathrm{kg}^{-1}$ & $\geq 4$ & $\geq 5$ \\
\hline$V^{\prime} \mathrm{E} \mathrm{L} \cdot \min ^{-1}$ & $\leq 15$ & $\leq 8.6$ \\
\hline $\mathrm{VC} / \mathrm{BW} \mathrm{mL} \cdot \mathrm{kg}^{-1}$ & $\geq 10$ & $\geq 13$ \\
\hline MIP $\mathrm{cmH}_{2} \mathrm{O}$ & $\geq 15$ & $\geq 44$ \\
\hline$P \mathrm{a}, \mathrm{O}_{2} / P \mathrm{~A}, \mathrm{O}_{2}$ & $\geq 0.35$ & $\geq 0.46$ \\
\hline$C_{\mathrm{rs}, \mathrm{eff}} \mathrm{mL} \cdot \mathrm{cmH}_{2} \mathrm{O}^{-1}$ & $\geq 22$ & $\geq 24$ \\
\hline$C \mathrm{rs}, \mathrm{st} \mathrm{mL} \cdot \mathrm{cmH}_{2} \mathrm{O}^{-1}$ & $\geq 33$ & $\geq 54$ \\
\hline$\Delta P \mathrm{I} / \mathrm{MIP}$ & $\leq 0.3$ & $\leq 0.41$ \\
\hline$f_{\mathrm{R}} / V_{\mathrm{T}}$ breaths $\cdot \min ^{-1} \cdot \mathrm{L}^{-1}$ & $\leq 100$ & $\leq 84$ \\
\hline CROP $\mathrm{mL} \cdot \mathrm{breath}^{-1} \cdot \mathrm{min}^{-1}$ & $\geq 13$ & $\geq 16$ \\
\hline
\end{tabular}

*: from [1], except for vital capacity (VC)/body weight (BW) and inspiratory pressure swing $(\Delta P \mathrm{I})$ /maximal inspiratory pressure (MIP), which were from [10] and [11], respectively. $f \mathrm{R}$ : respiratory frequency; $V \mathrm{~T}$ : tidal volume; $V^{\prime} \mathrm{E}$ : minute ventilation; $\mathrm{Pa}, \mathrm{O}_{2}$ : arterial oxygen tension; $\mathrm{PA}, \mathrm{O}_{2}$ : alveolar oxygen tension; $C$ rs,eff: effective compliance of the respiratory system; $C$ rs,st: static compliance of the respiratory system; CROP: compliance, rate, oxygenation, pressure index $\left(C \mathrm{rs}\right.$,eff $\times 1 / f \mathrm{R} \times P_{\mathrm{a}}, \mathrm{O}_{2} / P \mathrm{~A}, \mathrm{O}_{2}$ $\times$ MIP). 
criteria of the authors' department, namely: 1) consciousness (normal orientation and thought processes); 2) haemodynamic stability without need for vasoactive drugs and absence of arrhythmias; 3) metabolic and electrolyte balance ( $\mathrm{pH} \geq 7.35$ and serum sodium, potassium, chlorine, calcium and magnesium ion concentrations within normal range); 4) normal kidney function (serum creatinine levels and azotaemia within normal range); 5) normal liver (no coagulopathy or hyperbilirubinaemia and transaminase activity within normal range); 6) normal digestive system function (no vomiting, diarrhoea or constipation); 7) near-resolution of the immediate cause of ARF (decreased sputum production, cough, wheezing and white blood cell count associated with absence of fever; and resolution of pneumonia on radiography); and 8) arterial oxygen saturation $\left(\mathrm{Sa}_{2} \mathrm{O}_{2}\right)>90 \%$ with inspiratory oxygen fraction $\leq 0.4$ during mechanical ventilation. A WS was registered when the patient was capable of spontaneous breathing during a 2-h T-piece weaning trial followed by extubation, which did not require reinstitution of mechanical ventilation within $48 \mathrm{~h}$. A WF was registered when the 2-h weaning trial was terminated because of respiratory distress and cardiovascular instability (tachypnoea, increased accessory muscle activity, diaphoresis, facial signs of distress, tachycardia, arrhythmias and hypotension) or if $\mathrm{Sa}_{\mathrm{a}} \mathrm{O}_{2}$ and/or the $\mathrm{pH}$ fell below $88 \%$ and 7.3, respectively. Extubation failure was defined when reinstitution of mechanical ventilation was required $<48 \mathrm{~h}$ after extubation. The latter was required in only two subjects: patient No. $1018 \mathrm{~h}$ after extubation because of respiratory acidosis and paradoxical breathing, and patient No. 19 after $36 \mathrm{~h}$ because of respiratory distress associated with fever. None of the patients exhibited upper airway problems (e.g. oedema) after extubation.

\section{Weaning indices}

The weaning indices used consisted in those previously used, listed in table 2 together with the corresponding threshold values.

\section{Procedure and data analysis}

Immediately before the weaning trials, the patients were ventilated in $\mathrm{A} / \mathrm{C}$ mode with constant flow, with the ventilator settings adjusted to achieve the lowest levels of minute ventilation $\left(V^{\prime} \mathrm{E}\right)$ and an $f \mathrm{R}$ compatible with relaxation of the respiratory muscle, without the need for sedatives or muscle relaxants. During passive mechanical ventilation, the following variables were read from the ventilator dials: $V \mathrm{~T}$ during mechanical ventilation $(V \mathrm{~T}, \mathrm{MV})$, peak airway pressure $(P$ peak $)$ and, with end-expiratory and end-inspiratory occlusions of $>3 \mathrm{~s}$, the static end-expiratory (PEEPtot) and end-inspiratory (Pplateau) occlusion pressures. The following criteria were used to confirm that the measurements had been obtained during relaxation: 1) no trigger activation, 2) stability of peak airway pressure during $\geq 10$ respiratory cycles; and 3 ) attainment of a plateau during the 3-s end-inspiratory and end-expiratory airway occlusions. For each variable, the mean value of three measurements was calculated.
The internal transducers of the ventilator underwent checks and calibration throughout the study period. In order to reduce the effect of the compliance of the system connecting the subjects to the ventilator on the respiratory mechanics measurements, a single length of standard low-compliance adult tubing was used and the humidifier omitted from the inspiratory line. The compliance of the system connecting the subjects to the ventilator was 0.1 $\mathrm{L} \cdot \mathrm{kPa}^{-1}$. The arterial oxygen tension $\left(\mathrm{Pa}_{\mathrm{a}} \mathrm{O}_{2}\right)$ /alveolar oxygen tension $\left(P \mathrm{~A}, \mathrm{O}_{2}\right)$ was also measured during this period of mechanical ventilation.

From the above measurements, the following indices were computed: a) static respiratory compliance $(C$ rs,st): $C$ rs,st $=V$ T,MV/ $(P$ plateau - PEEPtot $)$; and b) effective respiratory compliance $(C$ rs,eff): $C$ rs,eff $=V$ T,MV/(P peak - PEEPtot $)$ [10].

Spontaneous breathing. After the data during mechanical ventilation had been collected, the patients were disconnected from the ventilator and underwent the weaning trial, breathing spontaneously through the endotracheal tube with supplemental oxygen (T-tube). The inspired $\mathrm{O}_{2}$ concentration was adjusted to obtain an $\mathrm{S}_{\mathrm{a}, \mathrm{O}_{2}}$ of $\geq 90 \%$. Cardiac frequency, $f \mathrm{R}$ and $\mathrm{Sa}, \mathrm{O}_{2}$ were continuously monitored in order to verify haemodynamic and respiratory stability. All data were collected within the 5th and 10th min after the beginning of the T-piece trial. During this period, all patients exhibited haemodynamic and respiratory stability.

The respiratory variables were measured as follows. First, $f \mathrm{R}$ and $V^{\prime} \mathrm{E}$ were measured for $1 \mathrm{~min}$ during the first 2-3 min of the weaning trial using a calibrated Wright respirometer (Ferraris Medical, Enfield, UK). VT was calculated by dividing $V^{\prime}$ E by $f R$. Next, VC was measured with the same device by asking the patient to inspire and expire maximally. This manoeuvre was repeated three times at a comfortable frequency of once every $40 \mathrm{~s}$ and the highest value selected. In all instances, before each subsequent $\mathrm{VC}$ measurement, the $\mathrm{Sa}_{\mathrm{a}} \mathrm{O}_{2}$, cardiac frequency and $f \mathrm{R}$ had returned to baseline values. Subsequently, the inspiratory pressure swing $(\Delta P \mathrm{I})$ was obtained by measuring the amplitude of the negative swing in airway pressure during an occluded inspiration from functional residual capacity (FRC) [11]. Airway occlusions were performed using a noiseless pneumatic shutter (Mallinckrodt, Mirandola, Italy) placed on the inspiratory line of a two-way valve connected to the proximal end of the endotracheal tube. Occlusion of the inspiratory line during a control expiration allowed expiration but prevented inspiration. The equipment dead space (excluding the endotracheal tube) was $23 \mathrm{~mL}$. The shutter was controlled remotely by a physician and the $\Delta P$ I read on an aneroid manometer (NIF-Kit; Markos, Monza, Italy). The $\Delta P$ I value was derived from the mean of three repeated measurements performed at the comfortable frequency of one every 1 min. Using the same device, maximal inspiratory pressure (MIP) was determined by maintaining the airway occluded at FRC for $\geq 20 \mathrm{~s}$, as described by MARINI et al. [12]. The maximal value from three repeated manoeuvres was accepted.

During the measurement of $V^{\prime} \mathrm{E}, \mathrm{VC}$ and MIP, the $\mathrm{O}_{2}$ supply was temporarily suspended. However, during these brief periods the $\mathrm{Sa}_{\mathrm{a}} \mathrm{O}_{2}$ always remained $>90 \%$. 
Some of the weaning indices used are based on measurements made solely during mechanical ventilation (e.g. $C \mathrm{rs}$,eff) or spontaneous breathing (e.g. $f \mathrm{R} / V \mathrm{~T})$, whereas others include measurements made under both conditions (e.g. compliance, rate, oxygenation, pressure index (CR$\mathrm{OP}, C \mathrm{rs}$,eff $\left.\times 1 / f \mathrm{R} \times \mathrm{Pa}_{\mathrm{a}} \mathrm{O}_{2} / P \mathrm{~A}, \mathrm{O}_{2} \times \mathrm{MIP}\right)$.

\section{Statistical analysis}

Data are presented as mean \pm SEM. The approximate degree of normal distribution was calculated for each index. Student's paired data t-test was used for analysing normally distributed data and Wilcoxon rank-sum pair analysis was used in cases in which this approximation was valid in terms of kurtosis and skewness. The Bonferroni adjustment was utilized in assessing the differences between a WF and a WS. A p-value of $<0.05$ was taken as statistically significant.

The threshold values proposed by other authors for various weaning indices were used to evaluate their predictive power in the present patient population (table 2).

The following standard formulae were used to calculate the predictive power of the threshold values for each index: 1) sensitivity=true positive/(true positive + false negative); 2) specificity=true negative/(true negative + false positive); and 3) diagnostic accuracy=(true positive+true negative)/ (true positive+true negative + false positive + false negative). A true positive result was defined as occurring when a patient's test predicted a WS and weaning succeeded; a true negative result as occurring when a test predicted a WF and weaning failed; a false positive result when a test predicted a WS but weaning failed, and a false negative result when a test predicted a WF but weaning succeeded.

Based on the present results, the threshold values of the weaning indices in table 2 and their relative classification errors were computed de novo using discriminant analysis. The classification error, which was calculated as [(false negative + false positive)/(true positive + true negative + false positive + false negative) $] \times 100$, represents the proportion of patients who are not classified correctly by a test. The predictive power of each index was also assessed using receiver operating characteristic (ROC) curves. ROC curve analysis provides a powerful means of assessing a test's ability to discriminate between two groups of patients, with the advantage that the analysis does not depend on the threshold value selected. The area under the ROC curve for each index summarizes the per- formance of that index in predicting weaning outcome. In order to overcome the problem of underestimation of the area related to the rating method reported in the literature, a calculation system in which each point on the ROC curve was determined by changing the diagnostic judgement threshold along the curve of positive sample distribution percentiles was adopted [13-15].

\section{Results}

As shown in table 3 , in the present COPD population, most indices were significantly different between a WF and a WS. The corresponding threshold values, calculated by the discriminant analysis method, are given in table 4 together with the classification error and the area under the ROC curve. The classification error was $<20 \%$ for MIP, $\triangle P \mathrm{I} / \mathrm{MIP}$ and CROP, whereas the area under the ROC curves was $>0.9$ only for $\Delta P \mathrm{I} / \mathrm{MIP}$ and CROP.

The threshold values obtained in the present COPD population were within $10 \%$ of those reported for a nonhomogeneous patient population only for $V \mathrm{~T}$ and $C_{\mathrm{rs}}$,eff (table 2). The other threshold values differed markedly, especially those for $f \mathrm{R} V^{\prime} \mathrm{E}, C \mathrm{rs}, \mathrm{st}$ and MIP. Figure 1 depicts the individual values of MIP, $f \mathrm{R} / V \mathrm{~T}$ and CROP obtained in the present subjects during a WF and a WS together with the threshold values obtained in the present study and in the literature (table 2).

In the present COPD population, the predictive power of the threshold values of the various weaning indices reported in the literature were assessed in a nonhomogeneous patient population (table 2). As shown in table 5, the diagnostic accuracy was rather low, except for that of CROP.

\section{Discussion}

The main finding of the present study is that the threshold values of the weaning indices obtained previously in a nonhomogeneous population of patients differ from those pertaining to COPD patients (table 2). This is not surprising in view of the fact that the abnormalities in respiratory mechanics, pulmonary gas exchange, control of breathing and inspiratory muscle function differ among patients who require mechanical ventilation for different aetiologies [2-7]. Accordingly, threshold values should be determined separately for different patient populations.

Table 3. - Values of different weaning indices in 28 chronic obstructive pulmonary disease patients during a failed weaning trial (WF) and a successful weaning trial (WS)

\begin{tabular}{|c|c|c|c|c|c|c|c|c|c|c|c|c|c|}
\hline & $\begin{array}{c}f \mathrm{R} \\
\text { breaths. } \\
\text { min }^{-1}\end{array}$ & $\begin{array}{l}V \mathrm{~T} \\
\mathrm{~mL}\end{array}$ & $\begin{array}{l}V \mathrm{~T} / \mathrm{BW} \\
\mathrm{mL} \cdot \mathrm{kg}^{-1}\end{array}$ & $\begin{array}{c}V^{\prime} \mathrm{E} \\
\mathrm{L} \cdot \mathrm{min}^{-1}\end{array}$ & $\begin{array}{l}\mathrm{VC} / \mathrm{BW} \\
\mathrm{mL} \cdot \mathrm{kg}^{-1}\end{array}$ & $\begin{array}{c}\mathrm{MIP} \\
\mathrm{cmH}_{2} \mathrm{O}\end{array}$ & $\begin{array}{l}P \mathrm{a}, \mathrm{O}_{2} / \\
P \mathrm{~A}, \mathrm{O}_{2}\end{array}$ & $\begin{array}{c}C \text { rs,eff } \\
\mathrm{mL} \cdot \\
\mathrm{cmH}_{2} \mathrm{O}^{-1}\end{array}$ & $\begin{array}{c}C \mathrm{rs}, \mathrm{st} \\
\mathrm{mL} \cdot \\
\mathrm{cmH}_{2} \mathrm{O}^{-1}\end{array}$ & $\begin{array}{c}\Delta \mathrm{II}^{-} \\
\mathrm{cmH} \mathrm{H}_{2} \mathrm{O}\end{array}$ & $\Delta P \mathrm{I} / \mathrm{MIP}$ & $\begin{array}{c}f \mathrm{R} / V_{\mathrm{T}} \\
\text { breaths. } \\
\mathrm{min}^{-1} \cdot \mathrm{L}^{-1}\end{array}$ & $\begin{array}{c}\text { CROP } \\
\mathrm{mL} \cdot \text { breath }^{-1} \\
\min ^{-1}\end{array}$ \\
\hline WF Mea & 28 & 292 & 4.3 & 8.1 & 11.1 & 38 & 0.4 & 21.6 & 57.6 & 16 & 051 & 106 & 11.6 \\
\hline SI & 4 & 1 & & 2.8 & 1 & 7 & & & & & & & 4 \\
\hline WF Mean & 24 & 38 & 5 & 8.9 & 15.2 & 53 & 0 . & 25.3 & 51 & 12 & 0.3 & 6 & 31 \\
\hline & 4 & 131 & 1.7 & 2.3 & 5.6 & 11 & 0.1 & 7.1 & 17 & 4.0 & 0 . & 26 & 16 \\
\hline p-value & 0.001 & 0.001 & 0.001 & NS & 0.001 & 0.001 & 0.001 & 0.001 & NS & 0.05 & 0.001 & 0.001 & 0.001 \\
\hline
\end{tabular}

$f \mathrm{R}$ : respiratory frequency; $V \mathrm{~T}$ : tidal volume; $\mathrm{BW}$ : body weight; $V^{\prime} \mathrm{E}$ : minute ventilation; VC: vital capacity; MIP: maximal inspiratory pressure; $P \mathrm{a}, \mathrm{O}_{2}$ : arterial oxygen tension; $P \mathrm{~A}_{2} \mathrm{O}_{2}$ : alveolar oxygen tension; $C \mathrm{rs}$,eff: effective compliance of the respiratory system; $C \mathrm{rs}$,st: static compliance of the respiratory system; $\Delta P$ I: inspiratory pressure swing during airway occlusion; CROP: compliance, rate,

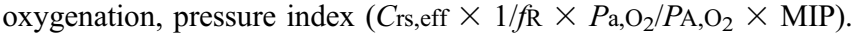


Table 4. - Threshold values of different weaning indices obtained in the present study

\begin{tabular}{|c|c|c|c|c|c|c|c|c|c|c|c|c|c|}
\hline & $\begin{array}{c}C \mathrm{rs}, \mathrm{st} \\
\mathrm{mL} \cdot \\
\mathrm{cmH}_{2} \mathrm{O}^{-1}\end{array}$ & $\begin{array}{c}V^{\prime} \mathrm{E} \\
\mathrm{L} \cdot \mathrm{min}^{-1}\end{array}$ & $\begin{array}{c}C \mathrm{rs}, \mathrm{eff} \\
\mathrm{mL} \cdot \\
\mathrm{cmH}_{2} \mathrm{O}^{-1}\end{array}$ & $\underset{\mathrm{cmH}}{\Delta \mathrm{II}_{2} \mathrm{O}}$ & $\begin{array}{l}P \mathrm{a}, \mathrm{O}_{2} / \\
P \mathrm{~A}, \mathrm{O}_{2}\end{array}$ & $\begin{array}{l}\mathrm{VC} / \mathrm{BW}^{-1} \\
\mathrm{~mL} \cdot \mathrm{kg}^{-1}\end{array}$ & $\begin{array}{l}V_{\mathrm{T}} \\
\mathrm{mL}\end{array}$ & $\begin{array}{l}V \mathrm{~T} / \mathrm{BW} \\
\mathrm{mL} \cdot \mathrm{kg}^{-1}\end{array}$ & $\begin{array}{c}f \mathrm{R} \\
\text { breaths. } \\
\text { min }^{-1}\end{array}$ & $\begin{array}{c}f \mathrm{R} / V \mathrm{~T} \\
\text { breaths. } \\
\min ^{-1} \cdot \mathrm{L}^{-1}\end{array}$ & $\underset{\mathrm{cmH}_{2} \mathrm{O}}{\mathrm{MIP}}$ & $\Delta P \mathrm{I} / \mathrm{MIP}$ & $\begin{array}{c}\text { CROP } \\
\mathrm{mL} \cdot \mathrm{breath}^{-1} . \\
\min ^{-1}\end{array}$ \\
\hline Threshold & 54 & 8.6 & 24 & 19.5 & 0.46 & 13 & 340 & 5.0 & 25 & 84 & 44 & 0.41 & 16 \\
\hline $\begin{array}{l}\text { Classification } \\
\text { error } \%\end{array}$ & 43 & 43 & 40 & 36 & 32 & 35 & 34 & 32 & 30 & 28 & 19 & 16 & 17 \\
\hline $\begin{array}{l}\text { ROC curve } \\
\text { area }\end{array}$ & 0.59 & 0.63 & 0.66 & 0.67 & 0.73 & 0.74 & 0.74 & 0.76 & 0.77 & 0.79 & 0.88 & 0.91 & 0.93 \\
\hline SEM & 0.08 & 0.08 & 0.07 & 0.07 & 0.06 & 0.07 & 0.07 & 0.07 & 0.07 & 0.04 & 0.05 & 0.04 & 0.04 \\
\hline
\end{tabular}

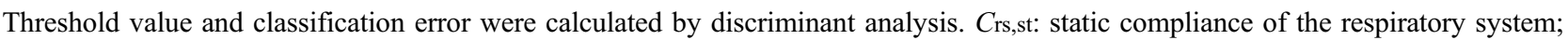
$V^{\prime} \mathrm{E}$ : minute ventilation; $C$ rs, eff: effective compliance of the respiratory system; $\Delta P$ I: inspiratory pressure swing during airway occlusion; $P \mathrm{a}, \mathrm{O}_{2}$ : arterial oxygen tension; $P \mathrm{~A}, \mathrm{O}_{2}$ : alveolar oxygen tension; $\mathrm{VC}$ : vital capacity; $\mathrm{BW}$ : body weight; $V \mathrm{~T}$ : tidal volume; $f \mathrm{R}$ : respiratory frequency; MIP: maximal inspiratory pressure; CROP: compliance, rate, oxygenation, pressure index $\left(C_{\mathrm{rs}, \text { eff }} \times 1 / f \mathrm{R} \times P \mathrm{a}, \mathrm{O}_{2} / P \mathrm{~A}, \mathrm{O}_{2} \times\right.$ MIP); ROC: receiver operating characteristic.

In the present study, the values of different weaning indices during a WF and a subsequent WS were assessed in the same 28 COPD patients, and the corresponding threshold values computed (table 4 ). The patients included two subjects (Nos.10 and 19) who had to be reintubated within $36 \mathrm{~h}$ after extubation. Since weaning and extubation failure may be regarded as distinct outcomes with different causes, the assessment of the parameters in tables 3 and 4 was repeated after exclusion of patients No. 10 and No. 19. The weaning threshold, classification error, ROC area and diagnostic accuracy remained virtually the same.

The classification error was lowest for $\Delta P \mathrm{I} / \mathrm{MIP}(16 \%)$, CROP (17\%) and MIP (19\%) and the corresponding ROC curve areas were highest $(0.91,0.93$ and 0.88 , respectively) (table 4). Clearly, the present threshold values for weaning indices need to be tested prospectively in future studies in COPD patients, which should also take into account the effect of duration of mechanical ventilation on weaning outcome [1]. However, the results of a recent study of VALLERDÙ et al. [16] suggest that the present threshold value for $f \mathrm{R} / V \mathrm{~T}$, which is lower than that proposed by YANG and ToBIN [1] (84 versus 100 breaths. $\left.\min ^{-1} \cdot \mathrm{L}^{-1}\right)$, is probably valid in COPD patients. They measured $f \mathrm{R} / V \mathrm{~T}$ in 13 COPD patients who were successfully weaned and 20 patients who failed weaning. The respective values for a WS and a WF were $59 \pm 32$ and
$110 \pm 50$ breaths $\cdot \mathrm{min}^{-1} \cdot \mathrm{L}^{-1}$, which are close to those of the present study (table 3). Furthermore, using a threshold value of $\leq 100$ breaths $\cdot \mathrm{min}^{-1} \cdot \mathrm{L}^{-1}$, they found a diagnostic accuracy similar to that of the present study ( 0.76 versus 0.71 ). Unfortunately these authors did not compute the threshold value of $f \mathrm{R} / V \mathrm{~T}$ using their data. It is likely, however, that it would have been $<100$, as in the present study (table 4). This is also supported by VASSILAKOPOULos et al. [17], who studied 10 COPD patients at two time points (during a WF and then a WS) and found similar $f \mathrm{R} /$ $V \mathrm{~T}$ values to those in the current study $(97 \pm 44$ breath$\mathrm{s} \cdot \mathrm{min}^{-1} \cdot \mathrm{L}^{-1}$ at failure and $51 \pm 11$ breaths $\cdot \mathrm{min}^{-1} \cdot \mathrm{L}^{-1}$ at success), indicating that in COPD a threshold of $<100$ breaths $\cdot \mathrm{min}^{-1} \cdot \mathrm{L}^{-1}$ should separate weaning failure from success. It should be noted that in the study of VAssiLAKOPOULOS et al. [17] the duration of mechanical ventilation did not play a prominent role in determining the weaning threshold.

Except for $V \mathrm{~T}$ and $C \mathrm{rs}$,eff, the threshold values of the weaning indices of the present COPD population differed markedly from those found in previous studies on nonhomogeneous populations of patients (table 2). This is especially true for $f \mathrm{R}, V^{\prime} \mathrm{E}, \mathrm{MIP}$, and $C$ rs,st.

According to YANG and TOBIN [1], the threshold values of $f \mathrm{R}$ and $V^{\prime} \mathrm{E}$ for predicting weaning outcome are $f \mathrm{R}$ $\leq 38$ breaths $\cdot \mathrm{min}^{-1}$ and $V^{\prime} \mathrm{E} \leq 15 \mathrm{~L} \cdot \mathrm{min}^{-1}$, respectively. These values, however, pertain to a nonhomogeneous
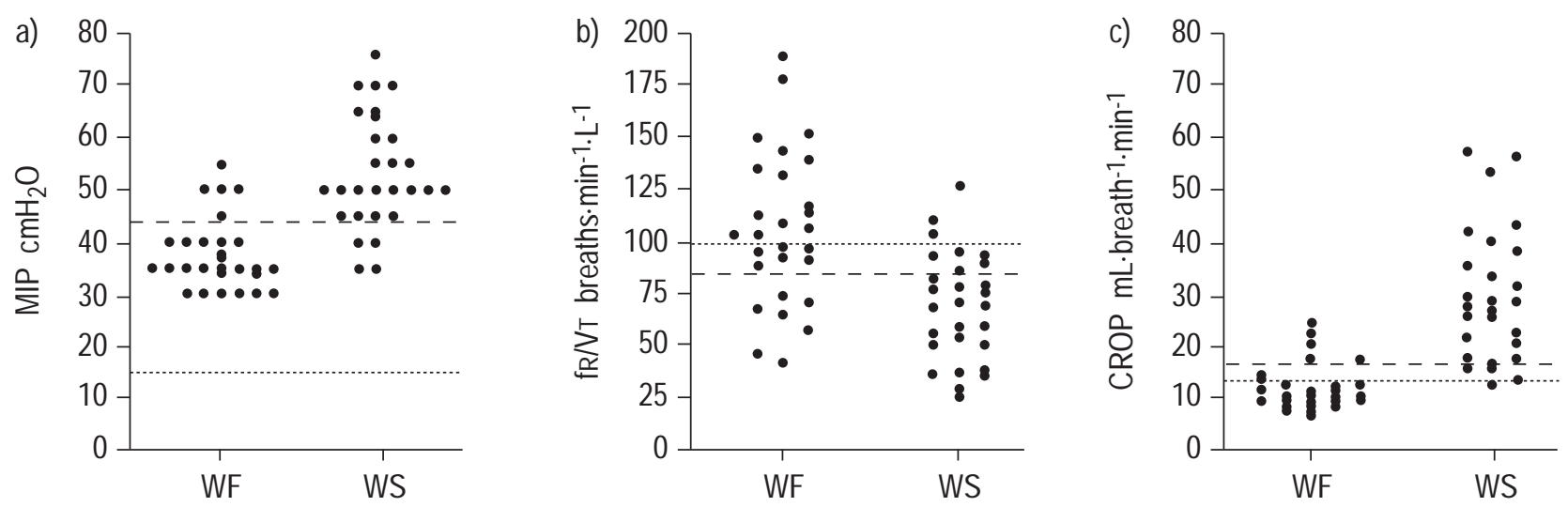

Fig. 1. - Individual values of three weaning indices obtained during a failed weaning trial (WF) and subsequently during a successful trial (WS) involving 28 chronic obstructive pulmonary disease patients. a) maximal inspiratory pressure (MIP); b) respiratory frequency $(f \mathrm{R})$ to tidal volume $(V \mathrm{~T})$ ratio; and c) compliance rate, oxygenation, pressure index (effective compliance of the respiratory system $\times 1 / f \mathrm{R} \times$ arterial oxygen tension/alveolar oxygen tension $\times$ MIP). ……. : threshold values from the literature (table 2); - - - : threshold values of the present study. For further information, see text. 
Table 5. - Sensitivity, specificity and diagnostic accuracy of different weaning indices using threshold values from previous studies*

\begin{tabular}{|c|c|c|c|c|c|c|c|c|c|c|c|c|}
\hline & $\begin{array}{c}\mathrm{Crs,st} \\
\mathrm{mL} \cdot \\
\mathrm{cmH}_{2} \mathrm{O}^{-1}\end{array}$ & $\begin{array}{c}V^{\prime} \mathrm{E} \\
\mathrm{L} \cdot \mathrm{min}^{-1}\end{array}$ & $\begin{array}{c}f \mathrm{R} \\
\text { breaths. } \\
\min ^{-1}\end{array}$ & $\begin{array}{c}\mathrm{MIP} \\
\mathrm{cmH}_{2} \mathrm{O}\end{array}$ & $\begin{array}{l}P \mathrm{a}, \mathrm{O}_{2} / \\
P A, \mathrm{O}_{2}\end{array}$ & $\begin{array}{l}\mathrm{VC} / \mathrm{BW} \\
\mathrm{mL} \cdot \mathrm{kg}^{-1}\end{array}$ & $\begin{array}{l}V_{\mathrm{T}} \\
\mathrm{mL}\end{array}$ & $\Delta P \mathrm{I} / \mathrm{MIP}$ & $\begin{array}{c}C \text { rs,eff } \\
\mathrm{mL} \cdot \\
\mathrm{cmH}_{2} \mathrm{O}^{-1}\end{array}$ & $\begin{array}{l}V \mathrm{~T} / \mathrm{BW} \\
\mathrm{mL} \cdot \mathrm{kg}^{-1}\end{array}$ & $\begin{array}{c}f \mathrm{R} / V \mathrm{~T} \\
\text { breaths. } \\
\min ^{-1} \cdot \mathrm{L}^{-1}\end{array}$ & $\begin{array}{c}\text { CROP } \\
\mathrm{mL} \cdot \text { breath }^{-1} . \\
\min ^{-1}\end{array}$ \\
\hline Sensitivity & 0.86 & 0.75 & 1.0 & 1.0 & 0.96 & 0.86 & 0.57 & 0.36 & 0.71 & 0.89 & 0.36 & 0.96 \\
\hline Specificity & 0.11 & 0.21 & 0 & 0 & 0.32 & 0.46 & 0.71 & 0.96 & 0.64 & 0.46 & 0.54 & 0.79 \\
\hline $\begin{array}{r}\text { Diagnostic } \\
\text { accuracy }\end{array}$ & 0.48 & 0.48 & 0.50 & 0.50 & 0.64 & 0.66 & 0.66 & 0.66 & 0.68 & 0.68 & 0.71 & 0.87 \\
\hline
\end{tabular}

*: in table 2. Sensitivity=true positive/(true positive + false negative); Specificity=true negative/(true negative + false positive); diagnostic accuracy $=($ true positive + true negative $) /($ true positive + false negative + false positive+true negative $)$. $C$ rs,st: static compliance of the respiratory system; $V^{\prime} \mathrm{E}$ : minute ventilation; $f \mathrm{R}$ : respiratory frequency; MIP: maximal inspiratory pressure; $P \mathrm{a}, \mathrm{O}_{2}:$ arterial oxygen tension; $P \mathrm{~A}, \mathrm{O}_{2}$ : alveolar oxygen tension; $\mathrm{VC}$ : vital capacity; $\mathrm{BW}$ : body weight; $V \mathrm{~T}$ : tidal volume; $\Delta P \mathrm{I}$ : inspiratory pressure swing during airway occlusion; $C$ rs, eff: effective compliance of the respiratory system; CROP: compliance, rate, oxygenation, pressure index ( $C$ rs,eff $\left.\times 1 / f \mathrm{R} \times P_{\mathrm{a}, \mathrm{O}_{2}} / P \mathrm{~A}, \mathrm{O}_{2} \times \mathrm{MIP}\right)$.

population. In COPD patients with $\mathrm{ARF}$, both $\mathrm{fR}$ and $V^{\prime} \mathrm{E}$ during spontaneous breathing are in general much lower than this [18-20]. This is in line with the present results: in both WF and WS patients, $f \mathrm{R}$ and $V^{\prime} \mathrm{E}$ were in most instances $<38$ breaths $\cdot \mathrm{min}^{-1}$ and $\leq 15 \mathrm{~L} \cdot \mathrm{min}^{-1}$, respectively (table 3 ). Furthermore, $V^{\prime} \mathrm{E}$ did not differ substantially among the WS and WF patients. Accordingly, in COPD, the thresholds for $f \mathrm{R}$ and $V^{\prime} \mathrm{E}$ were necessarily lower than those obtained by YANG and ToBIN [1] in a nonhomogeneous population (table 2).

In the present COPD patients, the $C$ rs, st measured during mechanical ventilation were relatively high (table 3 ), reflecting the fact that, in COPD patients with ARF, the $C$ rs,st does not differ significantly from that of normal subjects $[4,10]$, except on the first day of mechanical ventilation, when they exhibit marked dynamic hyperinflation and hence their $V \mathrm{~T}$ impinges on the flat upper part of the static volume/pressure curve of the respiratory system [2]. It should be noted, however, that during spontaneous breathing trials COPD patients may exhibit markedly enhanced dynamic hyperinflation (DH) with concomitant decrease in $C$ rs,st. This enhanced $\mathrm{DH}$ is closely associated with weaning failure [19, 20]. This may explain why $C_{\mathrm{rs}}$,st as well as $C_{\mathrm{rs}}$,eff, measured during mechanical ventilation, are of poor predictive power for weaning outcome (table 4).

The threshold values of MIP obtained in the present COPD patients differed markedly from that of YANG and ToBIN [1] (44 versus $15 \mathrm{cmH}_{2} \mathrm{O}$ ). Since the same method was used in both studies [12], this discrepancy probably mainly reflects differences between the populations studied. The present MIP threshold is also higher than that reported by other investigators $\left(\sim 30 \mathrm{cmH}_{2} \mathrm{O}\right)$ for a nonhomogeneous patient population [11] and for a group consisting predominantly of postoperative patients with a mean duration of mechanical ventilation of $36 \mathrm{~h}$ [21]. Since these investigators also used the occlusion method of MARINI et al. [12] to assess MIP, it is likely that the present high MIP threshold value reflects the different patient populations studied. It should be noted that, in COPD patients, MIP depends markedly on the extent of $\mathrm{DH}$, which in turn is modulated by several mechanisms (e.g. $V^{\prime} \mathrm{E}$, respiratory pattern and expiratory flow limitation). Decreased DH should result not only in increased MIP but also in a decrease in inspiratory load of breathing (decreased intrinsic positive end-expiratory pressure and increased $C$ rs,st). Accordingly, it is not surprising that, in COPD patients, MIP had a relatively high predictive power for weaning outcome, the ROC area amounting to 0.88 (table 4). Coussa et al. [5] predicted that COPD patients with ARF require a MIP of $<35 \mathrm{cmH}_{2} \mathrm{O}$ in order to be successfully weaned. In the present COPD patients, the MIP threshold value amounted to $44 \mathrm{cmH}_{2} \mathrm{O}$ (table 4).

Although in the present COPD patients MIP, an expression of inspiratory muscle strength, exhibited a relatively low classification error $(19 \%)$ (table 4$)$, the latter could be further reduced by indices which in addition to MIP also take into account inspiratory muscle activity $(\triangle P \mathrm{I} / \mathrm{MIP})$ as well as gas exchange and respiratory mechanics (CROP).

In the present COPD patients, the $f \mathrm{R} / V_{\mathrm{T}}$ threshold of 100 breaths $\cdot \mathrm{min}^{-1} \cdot \mathrm{L}^{-1}$ was associated with a relatively high classification error $(28 \%)$, contrary to the results obtained by YANG and TOBIN [1] in a nonhomogeneous patient population. This probably reflects the fact that in COPD patients the $f \mathrm{R} / V \mathrm{~T}$ threshold for predicting weaning outcome is lower than that reported by these authors $(84$ versus 100 breaths $\left.\cdot \mathrm{min}^{-1} \cdot \mathrm{L}^{-1}\right)$. A lower $f \mathrm{R} / V \mathrm{~T}$ threshold in COPD patients would be expected in view of their relatively low $f \mathrm{R}$ (see above). It should be noted, however, that the predictive value of $f \mathrm{R} / V \mathrm{~T}$ for weaning outcome found in the present COPD patients was similar to that observed by several authors in nonhomogeneous patient populations [22-26].

The magnitude of the area under the ROC curve allows estimation of the predictive power independent of a specific threshold value. The large ROC curve areas of $\triangle P \mathrm{I} / \mathrm{MIP}$ and $\mathrm{CROP}$ indicate that these indices potentially have a high predictive power for weaning outcome in COPD patients (table 4). Weaning failure in the present patients, in whom the extrapulmonary and metabolic abnormalities had already been corrected, was probably mainly due to excessive respiratory impedance and/or decreased inspiratory muscle strength. The results of this study indicate that the balance between load and strength is taken into account by weaning indices such as $\Delta P \mathrm{I} / \mathrm{MIP}$ and CROP, which can be measured at the bedside.

Patients should be weaned as soon as they can sustain spontaneous ventilation. Some experienced ICU physicians have the capacity to successfully predict whether or not a patient is ready for extubation solely on clinical examination. This, however, is not always the case. In fact, 
in the present initial weaning trial on 81 COPD patients, the ICU physicians correctly predicted a WS in only 53 $(65 \%)$ cases. Using MIP, $\triangle P \mathrm{I} / \mathrm{MIP}$ and CROP, a higher success rate would be expected (table 4). Thus, physiological weaning indices may help in such decisionmaking. A weaning index is clinically useful if: 1) it is related to the physiological mechanisms underlying ARF, 2 ) its diagnostic accuracy is adequate, and 3) its measurement is easy and reproducible. At present, a gold standard weaning index is not available, particularly for COPD patients. However, the present results suggest that $\Delta P \mathrm{I} /$ MIP and CROP may be a good candidates for such a role.

The main result of the present study is that, in chronic obstructive pulmonary disease patients who had already failed a first weaning attempt, the threshold values of most weaning indices differed from those of a whole nonhomogeneous population of mechanically ventilated patients undergoing a weaning trial.

\section{References}

1. Yang KL, Tobin MJ. A prospective study of indexes predicting the outcome of trials of weaning from mechanical ventilation. $N$ Engl J Med 1991; 324: 1445-1450.

2. Broseghini C, Brandolese R, Poggi R, et al. Respiratory mechanics during the first day of mechanical ventilation in patients with pulmonary edema and chronic airway obstruction. Am Rev Respir Dis 1981; 38: 355-361.

3. Eissa NT, Ranieri VM, Corbeil C, et al. Analysis of behavior of the respiratory system in ARDS patients: effects of flow, volume and time. J Appl Physiol 1991; 70: 27192729.

4. Guérin C, Coussa ML, Eissa NT, et al. Lung and chest wall mechanics in mechanically ventilated COPD patients. J Appl Physiol 1993; 74: 1571-1580.

5. Coussa ML, Guérin C, Eissa NT, et al. Partitioning of work of breathing in mechanically ventilated COPD patients. J Appl Physiol 1993; 75: 1711-1719.

6. Tantucci C, Corbeil C, Chassé M, Brady J, Matar N, Milic-Emili J. Flow resistance in mechanically ventilated patients with severe neurological injury. J Crit Care 1993; 8: 133-139.

7. Guérin C, LeMasson S, DeVarax R, Milic-Emili J, Fournier G. Small airway closure and positive end-expiratory pressure in mechanically ventilated patients with chronic obstructive pulmonary disease. Am J Respir Crit Care Med 1997; 155: 1949-1956.

8. American Thoracic Society. Standards for the diagnosis and care of patients with chronic obstructive pulmonary disease (COPD) and asthma. Am Rev Respir Dis 1987; 136: 225-243.

9. Morris JF, Koski A, Johnson LC. Spirometric standards for healthy nonsmoking adults. Am Rev Respir Dis 1971; 103: 57-67.

10. Rossi A, Polese G, Milic-Emili J. Monitoring respiratory mechanics in ventilator-dependent patients. In: Tobin MJ, ed. Principles and Practice of Intensive Care Monitoring. McGraw-Hill, 1997; pp. 569-570.
11. Yang KL. Inspiratory pressure/maximal inspiratory pressure ratio: a predictive index of weaning outcome. Intensive Care Med 1993; 19: 204-208.

12. Marini JJ, Smith TC, Lamb VJ. Estimation of inspiratory muscle strength in mechanically ventilated patients: the measurement of maximal inspiratory pressure. J Crit Care 1986; 1: 32-38.

13. Beck JB, Shultz EK. The use of relative operating characteristic (ROC) curves in test performance evaluation. Arch Pathol Lab Med 1986; 110: 13-20.

14. Metz CE. Basic principle of ROC analysis. Semin Nucl Med 1987; 8: 283-298.

15. Centor RM, Schwartz JS. An evaluation of methods for estimating the area under the receiver operating characteristic (ROC) curve. Med Decis Making 1985; 5: 149_ 156.

16. Vallverdú I, Calaf N, Subirana M, Net A, Benito S, Mancebo J. Clinical characteristics, respiratory functional parameters, and outcome of a two-hour T-piece trial in patients weaning from mechanical ventilation. Am J Respir Crit Care Med 1998; 158: 1855-1862.

17. Vassilakopoulos T, Zakynthinos S, Roussos C. The tension-time index and the frequency/tidal volume ratio are the major pathophysiologic determinants of weaning failure and success. Am J Respir Crit Care Med 1998; 158: 378-385.

18. Aubier M, Murciano D, Fournier M, Milic-Emili J, Pariente R, Derenne JF. Central respiratory drive in acute respiratory failure of patients with chronic obstructive lung disease. Am Rev Respir Dis 1980; 122: 191-199.

19. Murciano D, Boczkowsky J, Lecocguic Y, Milic-Emili J, Pariente R, Aubier M. Tracheal occlusion pressure: a simple index to monitor respiratory muscle fatigue during acute respiratory failure in patients with chronic obstructive pulmonary disease. Am Int Med 1988; 108: 800-805.

20. Aubier M, Murciano D, Milic-Emili J, et al. Effects of the administration of $\mathrm{O}_{2}$ on ventilation and blood gases in patients with chronic obstructive pulmonary disease during acute respiratory failure. Am Rev Respir Dis 1980; 122: 747-754.

21. Sahn SA, Lakshminarayan S. Bedside criteria for discontinuation of mechanical ventilation. Chest 1973; 63: 1002-1005.

22. Jubran A, Tobin MJ. Pathophysiologic basis of acute respiratory distress in patients who fail a trial of weaning from mechanical ventilation. Am J Respir Crit Care Med 1997; 155: 906-915.

23. Jubran A, Tobin MJ. Passive mechanics of lung and chest wall in patients who failed or succeeded in trials of weaning. Am J Respir Crit Care Med 1997; 155: 916-921.

24. Epstein SK. Etiology of extubation failure and the predictive value of the rapid shallow breathing index. $A m J$ Respir Crit Care Med 1995; 152: 545-549.

25. Chatila W, Jacob B, Guaglionone D, Manthous CA. The unassisted respiratory rate-tidal volume ratio accurately predicts weaning outcome. Am J Med 1996; 101: 61-67.

26. Jacob B, Chatila W, Manthous CA. The unassisted respiratory rate/tidal volume ratio accurately predicts weaning outcome in postoperative patients. Crit Care Med 1997; 25: 253-257. 